Original Research Paper

\title{
Effect of Cell Phone-Emitted Electromagnetic Waves on Levels of Male Sex Hormones and Oxidative Stress Biomarkers in Humans
}

\author{
${ }^{1}$ Abdelgawad Fahmi, ${ }^{2}$ Amal Saad-Hussein, ${ }^{2}$ Khadiga S Ibrahim, \\ ${ }^{3}$ Amal Madboly and ${ }^{1 *}$ Mariam Abdur-Rahman \\ ${ }^{I}$ Department of Chemistry, Faculty of Science, Cairo University, Giza, Egypt \\ ${ }^{2}$ Department of Environmental and Occupational Medicine, National Research Centre, Dokki, Giza, Egypt \\ ${ }^{3}$ Blood Bank, General Fayoum Hospital, Fayoum, Egypt
}

\author{
Article history \\ Received: 06-05-2021 \\ Revised: 09-07-2021 \\ Accepted: 12-07-2021 \\ Corresponding Author: \\ Mariam Abdur-Rahman \\ Department of Chemistry, \\ Faculty of Science, Cairo \\ University, Giza, Egypt \\ Email: mariam@sci.cu.edu.eg
}

\begin{abstract}
Cell phones emit Electromagnetic Waves (EMWs) that may have adverse effects on human health. The study aimed to investigate some possible health impacts associated with cell phone-derived EMWs on male sex hormones and oxidative stress biomarkers. One-hundred recruited male volunteers were classified into two equal groups; group 1 who used mobile phones less than one hour per day for less than five years and group 2 who used mobile phones more than one hour per day for more than five years which then subdivided into 3 groups according to the duration of usage in daily hours and annual usage. Sex hormones (testosterone, luteinizing hormone, follicle-stimulating hormone) as well as oxidative stress biomarkers (malondialdehyde and superoxide dismutase) were investigated. In comparison to group 1, group 2 showed a significant decrement in the blood levels of both testosterone and superoxide dismutase, which is accompanied by an increment in levels of luteinizing and follicle-stimulating hormones as well as malondialdehyde. Moreover, among group 2 subjects that used mobile for $>3 \mathrm{~h}$ /day for $>15$ years showed highly significant differences than those who used mobile for shorter periods, meaning that duration of exposure to mobile has serious clinical significance. Findings from our study confirmed that long-term use of cell phones can cause alteration in male sex hormones as well as a redox imbalance characterized by increased lipid peroxidation and decreased antioxidant biomarkers.
\end{abstract}

Keywords: Cell Phones, Electromagnetic Waves, Malondialdehyde, Oxidative Stress, Testosterone

\section{Introduction}

People around the world are frequently exposed to Electromagnetic Waves (EMWs) coming from many sources, such as televisions, base stations, radios, computer devices and cell phones (Vesselinova, 2015).

Cell phone technology has introduced new wireless applications, which in turn increases human exposure to EMWs (Kumari et al., 2017). Nowadays, cell phones are considered a vital part of routine life and are widely spread among all ages especially adults. It has been noticed that people are currently spending long hours with their cell phones for different purposes. However, the problem is that these devices are operating in band frequencies of $400-2000 \mathrm{MHz}$ and hence, they extensively emit EMWs (Al-Bayyari, 2017).
Although cell phones had gained global acceptance as an important part of life without minding about their impact on human health, early studies had supposed a possible link between cell phone usage and human health; as human bodies can act as EMWs antennas while such devices are transmitting signals to the base stations (Kesari et al., 2011). Furthermore, (Kesari et al., 2013) reported that human exposure to EMWs did cause testicular Leydig cells dysfunction and shrinkage of seminiferous tubules, which consequently led to a reduction in serum testosterone level as well as both sperm motility and count. More specifically, EMWs generated by cell phones were found to have significant effects on the male sex hormones. This problem is thought to be raised due to carrying cellular phones in a trouser 
pocket or clipped to waist belts near the external reproductive organs, especially testes, while using a hands-free technology such as Bluetooth earpieces. These habits increase the stress on the testes by cell phone emitted EMWs and put the male reproductive system at a big risk by causing spermatogenetic dysfunction and changing the sperm cell cycle following the deformation of testicular Leydig and Sertoli cells affecting cell proliferation and male sex hormones production (Cetkin et al., 2017; Oh et al., 2018).

On the other hand, free radicals resulted from oxygen metabolism, known as Reactive Oxygen Species (ROS), are continuously trapped by antioxidants present in the body tissues. But, when the production of ROS exceeds the scavenging capacity of antioxidants, Oxidative Stress (OS) is induced (i.e., imbalance between ROS generation and antioxidant defence), which leads to serious damaging effects on various systems of the human body (Ashok et al., 2014; He et al., 2017).

Our study aimed to investigate some possible health impacts associated with EMWs emitted or transmitted via cell phones such as their effects on male sex hormones and oxidative stress biomarkers.

\section{Materials and Method}

\section{Study Population}

A cross-sectional comparative study was conducted on one-hundred recruited male volunteers classified into two groups: Group 1 who used mobile phones for less than one hour for less than 5 years and group 2 who used the mobile phone for more than one hour for more than five years. All subjects were not on any medications and none of them was complaining of chronic diseases such as diabetes and hypertension. The participants were informed about the study design and its benefits to individuals and society as a whole. Written informed consent was obtained before recruitment. They were asked about their age, health state, medications, how long they used cell phones and their daily usage. Smokers, alcohol consumers together with patients with diabetes, hypertension, cardiac and genetic diseases were excluded from the present study.

\section{Blood Samples Collection}

A 5-ml blood sample was collected from each subject using sterile disposable syringes. For plasma preparation, $1 \mathrm{ml}$ of the whole blood was dispensed into the heparin bottle and used for estimation of Superoxide Dismutase enzyme (SOD). For serum preparation, the remaining 4 $\mathrm{ml}$ of whole blood were dispensed into a plain bottle and allowed to clot, retracted and spun at $3000 \mathrm{rpm}$ for $10 \mathrm{~min}$. The serum was divided into three aliquots and stored at $4{ }^{\circ} \mathrm{C}$ until use for other tests.

\section{Determination of Superoxide Dismutase (SOD) Levels}

SOD level in plasma was determined using heparinized blood samples and freshly reconstituted reagents. This assay depends on the ability of the SOD enzyme to inhibit the phenazine methosulfate-mediated reduction of Nitro blue tetrazolium dye. Following protocol (Nishikimi et al., 1972), the enzymatic activity of SOD was measured at a wavelength of $560 \mathrm{~nm}$ in erythrocyte lysate, using the commercially available kit (Biodiagnostic, Giza- Egypt).

\section{Determination of Malondialdehyde (MDA) Levels}

MDA was estimated by its thiobarbituric acid reactivity according to the method described by (Satoh, 1978), using the commercially available kit (Biodiagnostic, Giza- Egypt). In this assay, thiobarbituric acid (pink chromogenic substance) reacts with serum MDA at $95{ }^{\circ} \mathrm{C}$ for $30 \mathrm{~min}$ in an acidic medium. Consumption of thiobarbituric acid reagent could be detected spectrophotometrically by measuring the decrease in absorbance at $\lambda 534 \mathrm{~nm}$, which is then directly proportional to serum MDA level.

\section{Determination of Serum Sex Hormones}

Follicle-Stimulating Hormone (FSH), Luteinizing Hormone (LH) and testosterone were measured by Human Enzyme-Linked Immunosorbent Assay (ELISA) Abcam kits (ab108641, ab108651 and ab174569, respectively), which are designed for accurate quantitative measurement of hormones in human serum. Briefly, for each tested sex hormone, a 96-well plate has been pre-coated with the corresponding anti-hormone antibody. Serum samples (in parallel to standards) were then added into the wells and the hormone was allowed to bind to the pre-coated antibody. After incubation and washing, the anti-antibody-enzyme conjugate was added and left to bind to the antibody-hormone complex. After incubation, the wells were washed to remove unbound material and the substrate was then added and allowed to be catalyzed by the enzyme conjugate to produce blue coloration. The reaction was then terminated by the addition of a stop solution to stop the color development. The intensity of the signal was measured at $\lambda 450 \mathrm{~nm}$, which is directly proportional to the concentration of hormone in serum (Zheng et al., 2018).

\section{Statistical Analysis}

Statistical analysis was performed using the Statistical Package for Social Sciences (SPSS) software version 23.0. Independent t-test was used to compare quantitative results between two groups, while ANOVA and post-hoc LSD were used to compare more than two groups. P-value $<0.05$ was considered statistically significant. 


\section{Results}

\section{Demographic Characteristics of the Studied Subjects}

All the included subjects in the two groups were males and their ages were matched $(34.04 \pm 4.7$ and 34.1 \pm 4.8 , respectively) without significant difference $(\mathrm{P}$-value $=0.9)$.

\section{Laboratory Investigations of Biochemical Parameters}

Results show that there is a highly significant increase in FSH, LH and MDA in group 2 compared to group 1. In addition, there is a highly significant decrease in the total testosterone and SOD in group 2 compared to group 1 (Table 1).

\section{Effect of the Duration of using Cell Phone in Years} on the Hormonal and Oxidative Antioxidants Levels

Table 2 shows that there is a highly significant increase in the level of FSH, LH and MDA in subjects who used mobile phones for more than 15 years compared to those obtained mobile phones for 5 to 10 years or those who obtained mobile phones for 10 to 15 years. While there is a highly significant decrease in the levels of testosterone and SOD in the subjects who used mobile phones for more than 15 years compared to those who obtained mobile phones for 5 to 10 years or those who obtained mobile phones for 10 to 15 years.

\section{Effect of the Daily Duration in Hours Per Day of using Cell Phones on the Hormonal and Oxidative Antioxidants Levels}

Table 3 shows that there is no significant difference in the levels of FSH and LH in using mobile for more than 5 years (group 2) who were using mobile phones for less than $2 \mathrm{~h}$ /day compared to those using mobiles from 2 to 3 $\mathrm{h} /$ day or for more than $3 \mathrm{~h} /$ day. While using mobile phones more than $3 \mathrm{~h}$ /day causes a highly significant decrease in testosterone comparing to those using mobiles less than $2 \mathrm{~h}$. In addition, using mobile phones $>3 \mathrm{~h} /$ day causes an increase in MDA levels compared to those using mobile phone $<2 \mathrm{~h} /$ day and 2-3 h/day. Moreover, there is a significant decrease in SOD after using mobile phones $>3$ $\mathrm{h} /$ day than using mobile phones $<2 \mathrm{~h} /$ day and $2-3 \mathrm{~h} /$ day.

Table 1: Comparisons of the hormonal and oxidative antioxidants levels between the two main groups

\begin{tabular}{llll}
\hline Group & Group 1 $\mathrm{n}=50$ mean \pm SD & Group 2 $\mathrm{n}=50$ mean \pm SD & P-value \\
\hline FSH $(\mathrm{mIU} / \mathrm{ml})$ & $4.6 \pm 1.5$ & $5.9 \pm 3.05$ & 0.008 \\
LH $(\mathrm{mIU} / \mathrm{ml})$ & $3.06 \pm 1.8$ & $4.3 \pm 2.4$ & 0.005 \\
Testosterone $($ Total$)(\mathrm{ng} / \mathrm{ml})$ & $23.9 \pm 6.3$ & $19.5 \pm 6.9$ & 0.001 \\
MDA1 $(\mathrm{nmol} / \mathrm{ml})$ & $12.8 \pm 4.1$ & $16.1 \pm 5.2$ & 0.001 \\
SOD2 $(\mathrm{U} / \mathrm{gmHb})$ & $60.5 \pm 13.9$ & $53.0 \pm 10.8$ & 0.003 \\
\hline
\end{tabular}

FSH: Follicle Stimulating Hormone, LH: Luteinizing Hormone,

MDA: Malondialdehyde, SOD: Superoxide Dismutase

$* \mathrm{P}$-value $<0.05, * * \mathrm{P}$-value $<0.005$

Table 2: Effect of the duration of using cell phones on levels of sex hormones and oxidative antioxidant levels in group 2

\begin{tabular}{lllll}
\hline Group & $5-10$ years $\mathrm{n}=17$ mean \pm SD & $10-15$ years $\mathrm{n}=18$ mean \pm SD & $>15$ years $\mathrm{n}=15$ mean \pm SD & P-value \\
\hline FSH $(\mathrm{mIU} / \mathrm{ml})$ & $5 \pm 2.9^{\mathrm{a}^{* *}}$ & $5.5 \pm 2.2^{\mathrm{b}^{* *}}$ & $11.5 \pm 1.6$ & 0.001 \\
LH $(\mathrm{mIU} / \mathrm{ml})$ & $3.5 \pm 1.8^{\mathrm{a}^{* *}}$ & $4 \pm 2^{\mathrm{b}^{* *}}$ & $8.5 \pm 1.7$ & 0.001 \\
Testosterone $(\mathrm{ng} / \mathrm{ml})$ & $21 \pm 7.3^{\mathrm{a}^{*}}$ & $20 \pm 6.4^{\mathrm{b}^{*}}$ & $11.2 \pm 2.2$ & 0.02 \\
MDA $(\mathrm{nmol} / \mathrm{ml})$ & $16.6 \pm 3.9^{* * *}$ & $14 \pm 4^{\mathrm{b}^{* *}}$ & $25.4 \pm 6.5$ & 0.001 \\
SOD $(\mathrm{U} / \mathrm{gmHb})$ & $58.9 \pm 10.6^{\mathrm{a}^{* *}}$ & $52.4 \pm 8.3^{\mathrm{b}^{* *}}$ & $36.1 \pm 4.1$ & 0.001 \\
\hline
\end{tabular}

a: Significant difference between $5-10$ years and $>5$ years, b: Significant difference between 10-15years and $>5$ years, c: Significant difference between 5-10 years and 10-15 years $* \mathrm{P}$-value $<0.05, * * \mathrm{P}$-value $<0.005$

Table 3: Effect of the daily duration (hours/day) of using cell phone on sex hormones in group 2

\begin{tabular}{lllll}
\hline Group & $<2 \mathrm{~h} /$ day $\mathrm{n}=16$ mean $\pm \mathrm{SD}$ & $2-3 \mathrm{~h} /$ day $\mathrm{n}=16$ mean \pm SD & $>3 \mathrm{~h} /$ day $\mathrm{n}=18$ mean \pm SD & P-value \\
\hline FSH $(\mathrm{mIU} / \mathrm{ml})$ & $5.5 \pm 2.7$ & $5.6 \pm 2.7$ & $8.1 \pm 4.2$ & 0.09 \\
LH $(\mathrm{mIU} / \mathrm{ml})$ & $4 \pm 2.1$ & $4.2 \pm 2.3$ & $5.4 \pm 4.3$ & 0.3 \\
Testosterone $(\mathrm{ng} / \mathrm{ml})$ & $21.1 \pm 5.6^{\mathrm{a}^{*}}$ & $19.5 \pm 7.1$ & $14.2 \pm 8.8$ & 0.04 \\
MDA $(\mathrm{nmol} / \mathrm{ml})$ & $15.1 \pm 3.8^{\mathrm{a}^{* *}}$ & $15.2 \pm 3.3^{\mathrm{b}^{*}}$ & $21.2 \pm 8.9$ & 0.008 \\
SOD $(\mathrm{U} / \mathrm{gmH})$ & $57.6 \pm 7.8^{\mathrm{a}^{* *}}$ & $50.1 \pm 10.3^{\mathrm{c}^{*}}$ & $43.5 \pm 13$ & 0.001 \\
\hline
\end{tabular}

a: significant difference between $<2 \mathrm{~h} /$ day and $>3 \mathrm{~h} /$ day

b: significant difference between 2-3 h/day and $>3 \mathrm{~h} /$ day

c: significant difference between $<2 \mathrm{~h} /$ day and $2-3 \mathrm{~h} /$ day

$*$ P-value $<0.05, * * P$-value $<0.005$ 


\section{Discussion}

Nowadays, modern advances in cell phone applications, such as internet free-calls, chats, cameras, Bluetooth, YouTube and games, are associated with an increase in Electromagnetic Waves (EMWs) exposure (del Peral-Rosado et al., 2017), which has adverse effects on different body systems of both human and experimental animals (Mahdavi et al., 2014) and is considered as a stress factor that causes changes in the levels of male sex hormones (Asghari et al., 2016). This study aimed to study the effect of EMWs emitted from cellular phones on male sex hormones and oxidative/antioxidant biomarkers by comparing between two groups; group 1 who used cell phones for less than one hour for less than five years and group 2 who used cell phones for more than one hour a day for more than five years. Also, the study classified and compared case group members, according to the annual and daily duration of cell phone use in terms of (years) and (hours/day), respectively.

Results showed a highly significant increase in the mean \pm SD of FSH and LH accompanies by a highly significant decrease in the mean $\pm \mathrm{SD}$ of testosterone (total) in the group 2 that used cell phones compared to group 1. In agreement with the present results, (Oyewopo et al., 2017) found that long-term exposure to cell phone emitted-EMWs caused a state of testis dysfunction accompanied by decreased sex hormones levels concerning not only testosterone level but FSH and LH levels as well. Barbieri (2014; Darbandi et al., 2018) explained these effects on FSH and LH serum levels by the localization of FSH receptors and $\mathrm{LH}$ receptors on the testicular Sertoli and Leydig cells, respectively. However, (Aitken et al., 2005) made an experiment on adult rats that were exposed to $900-\mathrm{MHz}$ EMWs for $30 \mathrm{~min} /$ five days/week. No significant change has been observed in the weight of their testes or the relative percentage of the overall context of testicular interstitial tissue. But they had decreased serum levels of testosterone only, with no change in their LH and FSH levels. Exposure to EMWs affects the state of polarization of the cellular membrane. This polarization is responsible for many abnormalities in testosterone synthesis and secretion, which causes a decrease in the level of serum testosterone (Kesari and Behari, 2012). Additionally, (Sarookhani et al., 2010) investigated the in vivo effects of 950-MHz EMWs on the adrenal gland and sex organs of experimental animals. The decrease in testosterone level was found to be linked with EMWs-induced abnormalities in the reproductive system. Testes have a pivotal role in both spermatogenesis and steroidogenesis. Testosterone is the most important steroid hormone in the male reproductive system. It is produced by the testicular Leydig cells, which are very susceptible to EMWs effect that results in cell injury and then affects testosterone synthesis and serum level (Agarwal et al., 2011). Nazıroğlu et al. (2013) found that exposure of male rats to EMWs induced a reduction in the number of the testicular Leydig cells and hence, in testosterone production. Also, (Duan et al., 2014) reported that long-term exposure to EMWs may have adverse effects on fertility and leads to changes in sex hormone levels. This was attributed to the high sensitivity of the male reproductive organs to the surrounded environmental factors including EMWs, which are considered as a risk factor to male reproductive organs causing hormonal level changes. Additionally, (Sepehrimanesh et al., 2014) studied the exposure of male rats to EMWs for 30 days and reported a statistically significant decrease in serum testosterone levels in a longtime exposed group ( $4 \mathrm{~h}$ /day) compared to either short (1 $\mathrm{h}$ /day) or moderate ( $2 \mathrm{~h}$ /day) time exposure groups, which in agreement with our results. This decrease in testosterone levels was attributed to the damage in the testicular Leydig cells caused by EMWs resulted in an insufficient response to LH stimulation. Another study conducted by Qi et al. (2015) showed a significant decrease in testosterone hormonal levels in the serum of experimental rats after the exposure of $50 \mathrm{~Hz}$ EMWs for 18 weeks. Also, Asghari et al. (2016) have reported that exposure to EMWs causes alteration in serum level of testosterone.

In the present study, there was a significant increase in the mean $\pm \mathrm{SD}$ of serum Malondialdehyde (MDA) level in group 2 compared to group 1, however, there was a highly significant decrease in the mean $\pm \mathrm{SD}$ of Superoxide Dismutase (SOD) in group 2 compared to group 1, which agrees with results from Kesari et al. (2011) reporting that long-term exposure of male Wistar rats to cell phone-EMWs leads to a serum increase in MDA level and a decrease in SOD level. Also, La Vignera et al. (2012) reported an increase in oxidative stress following exposure to cell phone-EMWs in rodents' sperm cells. Another study by Meena et al. (2014) demonstrated that SOD enzymatic activity decreased after exposure to EMWs, which led to a decrease in the total antioxidant capacity in several organs. Nevertheless, studies designed to measure MDA levels and SOD activities have shown conflicting results (Jackson et al., 2016). Additionally, there were many studies conducted on animals that reported that the exposure to EMWs was associated with a significant increase in lipid peroxidation level (Ghanbari et al., 2013; Kumar et al., 2014; Pandey et al., 2017). In a study carried on human males, (El-Hamd and Aboeldahab, 2018) reported that the EMWs emitted from cell phones caused oxidative stress by increasing the lipid peroxidation rate and changing the antioxidants activity in the biological processes in the human body. Nowadays, modifications, technological applications and physical stresses are the most exogenous factors that induce Reactive Oxygen Species (ROS) production (Rakhit et al., 2013; Barazani et al., 2014; Sullivan and Chandel, 2014). Long-term exposure to 
EMWs can generate ROS in the male reproductive organs, causing not only reductions in count, viability and motility of the functional spermatozoa (La Vignera et al., 2012; Darbandi et al., 2017) but also disorders in male sex hormonal profiles (Darbandi et al., 2018). Antioxidants make a line of defence against any raise in ROS level. SOD enzyme is among the most important antioxidants (Rakhit et al., 2013; Darbandi and Darbandi, 2016). When the level of ROS increases exceeding the level of antioxidants, an imbalance between oxidants and antioxidants occurs and leads to Oxidative Stress (OS) that increases lipid peroxidation level (Darbandi and Darbandi, 2016). Adverse effects of high ROS levels on fertility occur both directly by inducing OS and indirectly by affecting hormone release (Darbandi and Darbandi, 2016; Retana-Márquez et al., 2009). Moreover, several studies showed an inhibitory effect of different stressors on hormonal levels (RetanaMárquez et al., 2009; Yaribeygi et al., 2017).

\section{Conclusion}

The current study proved that the long-term use of cell phones (for $>3 \mathrm{~h} /$ day for $>15$ years) has a serious clinical significance by leading to alterations in male sex hormones as it causes a highly significant increase in Follicle-Stimulating Hormone (FSH) and Luteinizing Hormone (LH) associated with a highly significant decrease in testosterone hormone. Also, oxidant/antioxidant biomarkers serum levels have been significantly affected by the same duration of exposure that caused a highly significant increase in Antioxidant Biomarker Malondialdehyde (MDA) associated with a highly significant decrease in oxidant biomarker Superoxide Dismutase (SOD), respectively. Hence, people should be aware of the serious side effects of long-term exposure to Electromagnetic Waves (EMWs) and try to limit their cell phone addiction as much as possible.

\section{Clinical Significance}

Long-term use of cell phones ( $>3 \mathrm{~h} /$ day $>15$ years) caused a significant change in the normal male sex hormones profile in serum of adult men, characterized by increased LH/FSH while decreased testosterone. This was accompanied by a redox-imbalance represented by a significantly increased level of serum malondialdehyde and decreased level of superoxide dismutase (i.e., antioxidant and oxidant biomarkers, respectively).

\section{Conflict of Interest}

The authors declared no conflict of interest.

\section{Authors' Contributions}

According to the relevant CRediT roles, authors' individual contributions are listed as follows.

Abdelgawad Fahmi: Conceptualization, methodology, investigation, validation, writing - review and editing and supervision.

Amal Saad-Hussein: Conceptualization, methodology, investigation, validation, writing review and editing and supervision.

Khadiga S Ibrahim: Conceptualization, methodology, investigation, validation, writing - review and editing and supervision.

Amal Madboly: Methodology, investigation, formal analysis, data curation, visualization and writing - original draft.

Mariam Abdur-Rahman: Conceptualization, methodology, investigation, validation, writing - review and editing, visualization and supervision.

\section{Ethics}

This article is original and contains unpublished material. The corresponding author confirms that all of the other authors have read and approved the manuscript and no ethical issues involved

\section{References}

Agarwal, A., Singh, A., Hamada, A., \& Kesari, K. (2011). Cell phones and male infertility: a review of recent innovations in technology and consequences. International braz $\mathrm{j}$ urol, 37, 432-454. https://www.scielo.br/j/ibju/a/Rg9yjCFyL3bHTwcL y8nGMsp/abstract/?format=html\&stop=previous\&la $\mathrm{ng}=\mathrm{en}$

Aitken, R. J., Bennetts, L. E., Sawyer, D., Wiklendt, A. M., \& King, B. V. (2005). Impact of radio frequency electromagnetic radiation on DNA integrity in the male germline. international journal of andrology, 28(3), 171-179. https://doi.org/10.1111/j.13652605.2005.00531.x

Al-Bayyari, N. (2017). The effect of cell phone usage on semen quality and fertility among Jordanian males. Middle East Fertility Society Journal, 22(3), 178-182. https://doi.org/10.1016/j.mefs.2017.03.006

Asghari, A., Khaki, A. A., Rajabzadeh, A., \& Khaki, A. (2016). A review on Electromagnetic fields (EMFs) and the reproductive system. Electronic physician, 8(7), 2655. https://doi.org/10.19082/2655

Ashok, A., Gurpriya, V., Chloe, O., \& Stefan, S. (2014). Effect of oxidative stress on Male Reproduction. The World Journal of Men's Health, 32(1), 1-17. https://doi.org/10.5534/wjmh.2014.32.1.1 
Barazani, Y., Katz, B. F., Nagler, H. M., \& Stember, D. S. (2014). Lifestyle, environment and male reproductive health. Urologic Clinics, 41(1), 55-66. https://www.urologic.theclinics.com/article/S00940143(13)00094-3/abstract

Barbieri, R. L. (2014). The endocrinology of the menstrual cycle. In Human Fertility (pp. 145-169). Humana Press, New York, NY. https://doi.org/10.1007/978-1-4939-0659-8_7

Cetkin, M. U. R. A., Kızılkan, N., Demirel, C., Bozdağ, Z., Erkılıç, S., \& Erbağcı, H. (2017). Quantitative changes in testicular structure and function in rat exposed to mobile phone radiation. Andrologia, 49(10), e12761. https://doi.org/10.1111/and.12761

Darbandi, M., Darbandi, S., Agarwal, A., Henkle, R., \& Sadeghi, M. R. (2017). The effects of exposure to low frequency electromagnetic fields on male fertility. Altern Ther Health Med, 23.

Darbandi, M., Darbandi, S., Agarwal, A., Sengupta, P., Durairajanayagam, D., Henkel, R., \& Sadeghi, M. R. (2018). Reactive oxygen species and male reproductive hormones. Reproductive Biology and Endocrinology, 16(1), 1-14. https://doi.org/10.1186/s12958-018-0406-2

Darbandi, S., \& Darbandi, M. (2016). Lifestyle modifications on further reproductive problems. Cresco Journal of Reproductive Science, 1(1), 1-2.

del Peral-Rosado, J. A., Raulefs, R., López-Salcedo, J. A., \& Seco-Granados, G. (2017). Survey of cellular mobile radio localization methods: From $1 \mathrm{G}$ to $5 \mathrm{G}$. IEEE Communications Surveys \& Tutorials, 20(2), 1124-1148.

https://ieeexplore.ieee.org/abstract/document/8226757/

Duan, W., Liu, C., Wu, H., Chen, C., Zhang, T., Gao, P., ... \& Zhou, Z. (2014). Effects of exposure to extremely low frequency magnetic fields on spermatogenesis in adult rats. Bioelectromagnetics, 35(1), 58-69. https://doi.org/10.1002/bem.21816

El-Hamd, M. A., \& Aboeldahab, S. (2018). Cell phone and male infertility: An update. Journal of Integrative Nephrology and Andrology, 5(1), 1. https://doi.org/10.4103/jina.jina_34_17

Ghanbari, M., Mortazavi, S. B., Khavanin, A., \& Khazaei, M. (2013). The effects of cell phone waves (900 MHz-GSM band) on sperm parameters and total antioxidant capacity in rats. International journal of fertility \& sterility, $7(1), \quad 21$. https://www.ncbi.nlm.nih.gov/pmc/articles/pmc3850 324/

He, L., He, T., Farrar, S., Ji, L., Liu, T., \& Ma, X. (2017). Antioxidants maintain cellular redox homeostasis by elimination of reactive oxygen species. Cellular Physiology and Biochemistry, 44(2), 532-553. https://www.karger.com/Article/Abstract/485089
Jackson, M. J., Vasilaki, A., \& McArdle, A. (2016). Cellular mechanisms underlying oxidative stress in human exercise. Free radical biology and medicine, 98, 13-17. https://doi.org/10.1016/j.freeradbiomed.2016.02.023

Kesari, K. K., \& Behari, J. (2012). Evidence for mobile phone radiation exposure effects on reproductive pattern of male rats: role of ROS. Electromagnetic biology and medicine, 31(3), 213-222. https://doi.org/10.3109/15368378.2012.700292

Kesari, K. K., Kumar, S., \& Behari, J. (2011). Effects of radiofrequency electromagnetic wave exposure from cellular phones on the reproductive pattern in male Wistar rats. Applied biochemistry and biotechnology, 164(4), 546-559. https://doi.org/10.1007/s12010010-9156-0

Kesari, K. K., Kumar, S., Nirala, J., Siddiqui, M. H., \& Behari, J. (2013). Biophysical evaluation of radiofrequency electromagnetic field effects on male reproductive pattern. Cell biochemistry and biophysics, 65(2), 85-96 https://link.springer.com/article/10.1007/s12013 012-9414-6

Kumar, S., Nirala, J. P., Behari, J., \& Paulraj, R. (2014). Effect of electromagnetic irradiation produced by $3 \mathrm{G}$ mobile phone on male rat reproductive system in a simulated scenario. http://nopr.niscair.res.in/handle/123456789/29335

Kumari, K., Capstick, M., Cassara, A. M., Herrala, M., Koivisto, H., Naarala, J., ... \& Juutilainen, J. (2017). Effects of intermediate frequency magnetic fields on male fertility indicators in mice. Environmental Research, 157, 64-70. https://doi.org/10.1016/j.envres.2017.05.014

La Vignera, S., Condorelli, R. A., Vicari, E., D'Agata, R., \& Calogero, A. E. (2012). Effects of the exposure to mobile phones on male reproduction: a review of the literature. Journal of andrology, 33(3), 350-356. https://doi.org/10.2164/jandrol.111.014373

Mahdavi, S. M., Sahraei, H., Yaghmaei, P., \& Tavakoli, H. (2014). Effects of electromagnetic radiation exposure on stress-related behaviors and stress hormones in male wistar rats. Biomolecules \& Therapeutics, 22(6), 570. https://doi.org/10.4062/biomolther.2014.054

Meena, R., Kumari, K., Kumar, J., Rajamani, P., Verma, H. N., \& Kesari, K. K. (2014). Therapeutic approaches of melatonin in microwave radiationsinduced oxidative stress-mediated toxicity on male fertility pattern of Wistar rats. Electromagnetic Biology and Medicine, 33(2), 81-91. https://doi.org/10.3109/15368378.2013.781035

Nazıroğlu, M., Yüksel, M., Köse, S. A., \& Özkaya, M. O. (2013). Recent reports of Wi-Fi and mobile phoneinduced radiation on oxidative stress and reproductive signaling pathways in females and males. The Journal of Membrane Biology, 246(12), 869-875. https://link.springer.com/article/10.1007/s00232013-9597-9 
Nishikimi, M., Roa, N.A., \& Yogi, K. (1972). The occurrence of Supeoxide Anion in the Reaction of Reduced Phenazine Methosulfate and Molecular Oxygen. Biochem. Biophys. Res. Commun. 46, 849854. doi: 10.1016/s0006-291x(72)80218-3.

Oh, J. J., Byun, S. S., Lee, S. E., Choe, G., \& Hong, S. K. (2018). Effect of electromagnetic waves from mobile phones on spermatogenesis in the era of 4G-LTE. BioMed Research International, 2018. https://doi.org/10.1155/2018/1801798

Oyewopo, A. O., Olaniyi, S. K., Oyewopo, C. I., \& Jimoh, A. T. (2017). Radiofrequency electromagnetic radiation from cell phone causes defective testicular function in male Wistar rats. Andrologia, 49(10), e12772. https://doi.org/10.1111/and.12772

Pandey, N., Giri, S., Das, S., \& Upadhaya, P. (2017). Radiofrequency radiation (900 MHz)-induced DNA damage and cell cycle arrest in testicular germ cells in swiss albino mice. Toxicology and Industrial Health, 33(4), 373-384. https://doi.org/10.1177/0748233716671206

Qi, G., Zuo, X., Zhou, L., Aoki, E., Okamula, A., Watanebe, M., ... \& Shimamoto, F. (2015). Effects of extremely low-frequency electromagnetic fields (ELF-EMF) exposure on B6C3F1 mice. Environmental Health and Preventive Medicine, 20(4), 287-293. https://doi.org/10.1007/s12199-015-0463-5

Rakhit, M., Gokul, S. R., Agarwal, A., \& du Plessis, S. S. (2013). Antioxidant strategies to overcome OS in IVF-Embryo transfer. In Studies on Women's Health (pp. 237-262). Humana Press, Totowa, NJ. https://link.springer.com/chapter/10.1007/978-162703-041-0_13

Retana-Márquez, S., Bonilla-Jaime, H., VázquezPalacios, G., \& Martínez-García, R. (2009). Naltrexone effects on male sexual behavior, corticosterone and testosterone in stressed male rats. Physiology and Behavior, 96(2), 333-342. https://doi.org/10.1016/j.physbeh.2008.10.022
Sarookhani, M. R., Rezaei, M. A., Safari, A., Zaroushani, V., \& Ziaeiha, M. (2010). The influence of $950 \mathrm{MHz}$ magnetic field (mobile phone radiation) on sex organ and adrenal functions of male rabbits. African journal of Biochemistry Research, 5(2), 77-80. https://academicjournals.org/journal/AJBR/articleabstract/898A44712184

Satoh, K. (1978). Serum lipid peroxide in cerebrovascular disorders determined by a new colorimetric method. Clinica Chimica Acta, 90(1), 37-43. https://doi.org/10.1016/0009-8981(78)90081-5

Sepehrimanesh, M., Saeb, M., Nazifi, S., Kazemipour, N., Jelodar, G., \& Saeb, S. (2014). Impact of $900 \mathrm{MHz}$ electromagnetic field exposure on main male reproductive hormone levels: a Rattus norvegicus model. International Journal of Biometeorology, 58(7), 1657-1663. https://doi.org/10.1007/s00484013-0771-7

Sullivan, L. B., \& Chandel, N. S. (2014). Mitochondrial reactive oxygen species and cancer. Cancer and Metabolism, 2(1), 1-12. https://link.springer.com/article/10.1186/2049-30022-17

Vesselinova, L. (2015). Body mass index as a risk prediction and prevention factor for professional mixed low-intensity EMF burden. Electromagnetic biology and medicine, 34(3), 238-243. https://doi.org/10.3109/15368378.2015.1076449

Yaribeygi, H., Panahi, Y., Sahraei, H., Johnston, T. P., \& Sahebkar, A. (2017). The impact of stress on body function: A review. EXCLI Journal, 16, 1057. https://doi.org/10.17179/excli2017-480

Zheng, R., Zhao, Y., Wu, J., Wang, Y., Liu, J. L., Zhou, Z. L., ... \& Li, J. D. (2018). A novel PNPLA6 compound heterozygous mutation identified in a Chinese patient with Boucher-Neuhäuser syndrome. Molecular Medicine Reports, 18(1), 261-267. https://doi.org/10.3892/mmr.2018.8955 